\title{
A ASCENSÃO DO OCIDENTE REPRESENTOU A ASCENSÃO DA LIBERDADE E DA OPULÊNCIA ${ }^{1}$
}

\author{
English Title: THE RISE OF THE WEST REPRESENTED THE RISE OF FREEDOM \\ AND OPULENCE
}

doi>10.33726/akdpapers2447-7656v12a72021p26-41

\author{
HIGGS, Robert ${ }^{2}$ \\ PESSOA, Marcelo ${ }^{3}$ - (iD https://orcid.org/0000-0002-9193-4604
}

RESUMO: A saída dos EUA do Afeganistão, em 2021, ao mesmo tempo em que assombrou o mundo, reaqueceu a memória das diferenças historicamente experienciadas entre o Oriente e o Ocidente. Fora do lugar comum que a Pandemia de COVID-19 faz focalizar na China o protagonismo sanitário, bélico, político e econômico de rupturas geopolíticas, o restante da Ásia, para a maior parte dos ocidentais, soa como território propenso ao exotismo, ao arcaísmo e, em certa medida, ao terrorismo internacional. Exceção feita à Índia quanto às tensões, é de boa parte deste Oriente Médio, Próximo e Distante que muitos dos abalos financeiros surgem. Num contexto em que a recuperação econômica global assume papel de relevância no pós-COVID19 , ler, entender e comentar os textos de Mr. Higgs não contempla apenas um objetivo editorial, mas, sobretudo, diante das temáticas do seleto corpus, traz em si justificativa sociocultural e, sem dúvida, redunda em inequívoco mérito científico (N. do E.).

\section{PALAVRAS-CHAVE: Oriente e Ocidente, COVID-19, Nota do Editor}

ABSTRACT: The US exit from Afghanistan in 2021, at the same time as it haunted the world, rekindled the memory of the historically experienced differences between East and West. Out of the commonplace that the COVID-19 Pandemic makes China focus on the sanitary, military, political and economic protagonism of geopolitical ruptures, the rest of Asia, for most Westerners, sounds like a territory prone to exoticism, archaism and, to some extent, to international terrorism. With the exception of India in terms of tensions, it is from much of this Middle, Near and Far East that many of the financial turmoil arise. Therefore, in a context in which the global economic recovery assumes a relevant role in the post-COVID-19 period, reading, understanding and commenting on Mr. Higgs' texts does not only contemplate an editorial objective, but, above all, given the themes of the select corpus, it brings with it sociocultural justification and, without a doubt, results in unmistakable scientific merit (N. do E.).

\section{KEYWORDS: East and West, COVID-19, Editor's Note}

\footnotetext{
${ }^{1}$ Texto publicado pelo Instituto Mises Brasil, em 16/08/2021. A equipe do AKEDIA Journal realizou a captação digital, revisões linguísticas e conferiu tratamento textual do original para o formato Artigo Científico Completo. Os comentários do Editor-Chefe da AKEDIA Journal, se fizeram necessários para o ajuste do texto de partida ao novo formato. Neste sentido, impusemos algumas "Notas do Editor" (N. do E.), nas quais buscamos, num rol de escritos do próprio Mr. Higgs, vieses de cotejamento que propusessem diálogos entre o título mais recente com o seu lastro de pensamento (Matriz disponível em: https://mises.org.br/article/2836/a-ascensao-do-ocidente-representou-a-ascensao-da-liberdade-e-daopulencia-?utm_campaign=carta_semanal_1808\&utm_medium=email\&utm_source=RD+Station).

${ }^{2}$ Robert Higgs, com 77 anos em 2021, é um economista e historiador da economia estadunidense, que combina os insights da Escola Austríaca de Economia, do Liberalismo Clássico, do Libertarismo em teoria política e legal e políticas públicas. Fundador do "The Independent Review: A Journal of Political Economy" (https://www.independent.org/aboutus/person_detail.asp?id=489), é PhD pela Johns Hopkins University (N. do E.).

${ }^{3}$ Editor-Chefe / AKEDIA Journal - assume a co-autoria, por meio das N. do E. inscritas nesta reedição.
} 


\section{INTRODUÇÃO - As causas desta façanha e a retração da China}

Ao longo de praticamente todo o período da história humana, privações materiais e insegurança crônica sempre foram a norma. A pobreza, e não a fartura, era o lugar o comum. Nem mesmo aquelas pessoas que estavam no topo da pirâmide social e do poder político podiam usufruir todos estes confortos básicos (como alimentação, habitação e vestuário) e prazeres consumistas que os "pobres" do mundo ocidental atual veem como naturais e corriqueiros.

Nesta primeira N. do E. imposta à Introdução, recuperamos de Mr. Higgs, um fragmento em que se tecem ponderações sobre a questão ideológica, a qual tende a normatizar certos contextos socioculturais. Como a constante ideológica é uma premissa basilar civilizatória e, em certos casos, determinantes do ritmo e da qualidade de vida das pessoas, quer tenha sido na Pré História, quer seja na Pré Pandemia, durante e no Pós-COVID-19, vale lembrar, que:

Em toda e qualquer situação, em qualquer época e em qualquer lugar do mundo, o que dominará o pensamento das pessoas, bem como a ação que elas exigirão de suas autoridades, é a ideologia dominante. A ideologia dominante possui o indelével poder de moldar a maneira como as pessoas interpretam o que está ocorrendo no campo social, por que isso está ocorrendo, e o que deve ser feito a respeito. A ideologia exerce seu poder em grande parte por meio daquilo que podemos chamar de poder da predisposição, isto é, o poder que ela possui de gerar conclusões padrões e predeterminadas, as quais, quando examinadas mais detidamente, nada mais são do que meros saltos de fé (HIGGS, 17/10/2013: N. do E.).

Portanto, é de se assegurar, que um viés ideológico, digamos, hostil, tal como visto em suas variáveis orientais mais ácidas, tenha, de fato, sido responsável por instituir, manter e perpetuar estratos sociais obscurecidos pela miséria, pela ignorância e posturas radicais, uma vez 
que a ideologia radical gera um tipo de submissão a uma conjuntura mandatária: este é o "poder que ela possui de gerar conclusões padrões e predeterminadas", segundo salienta Higgs (17/10/2013: N. do E.).

Em determinadas épocas, certas populações sobressaíam-se e usufruíam uma qualidade de vida superior - como talvez na Grécia antiga e em Roma, e na China durante a Dinastia Sung (960-1279) mas tais casos representavam a exceção.

No final do século XIV, os chineses provavelmente eram o povo que usufruía o mais alto nível de vida dentre todas as grandes populações do mundo. A admiração com que os europeus receberam os relatos de Marco Polo sobre a China, no final do século XIII - ainda que, como o próprio Polo houvesse declarado em seu leito de morte, ele não descrevera nem metade do que teria visto na China - é uma das provas desta superioridade chinesa.

Ao fim da Idade Média (a partir do Século XVI: N. do E.), os europeus começaram a apresentar um progresso econômico mais acelerado, ao passo que os chineses entraram em um processo de estagnação econômica. Ainda mais notável foi a alteração ocorrida na energia econômica da Europa, que começou a se distanciar dos grandes centros comerciais do norte da Itália e se moveu em direção à periferia da civilização, no noroeste da Europa (sobre itens de evolução e de atraso socioeconômico, consultar em nossas Referências, também: HIGGS, 24/07/2017: N. do E.).

Os bárbaros, aparentemente, haviam, de alguma forma, descoberto o segredo do progresso econômico. Como N. do E., vale dizer que o designativo "Bárbaro" foi a denominação romana dada àqueles que viviam além das fronteiras do Império e que não falavam o Latim. Dentre os principais grupos tidos como "Bárbaros", temos os: Germanos: de origem indo-europeia, compreendo povos como os "Vigiados", os "Ostrogodos", os "Vândalos", os "Bretões", os "Saxões", os 


\section{AKEDIA}

"Francos" etc. Havia, também, os Eslavos: provenientes da Europa Oriental e da Ásia, dentre os quais figuravam os "Russos", os "Tchecos", os "Poloneses", os "Sérvios", e outros. O último grande grupo Bárbaro, são os Tártaro-mongóis: origem asiática, formado basicamente pelas tribos dos "Hunos", dos "Turcos", dos "Búlgaros" e além destes.

Ainda em regime de N. do E., tomamos a liberdade de indagar o texto de Higgs que, neste ponto, deixa em suspensão a ideia sobre qual formato teria a Europa lançado mão para avançar economicamente face aos outros povos. Mais adiante neste paper, Mr. Higgs aporá algumas hipóteses - o que não traz impeditivo em apresentarmos a nossa. Assim, trouxemos como complemento de seu pensamento, a escravidão humana como um fato que, se não foi omitido originalmente por Higgs, no presente escrito, deve ter sido, no mínimo, alvo de suas reflexões:

Todas as sociedades da terra utilizam a escravidão. O corolário não-explícito é que todas as sociedades devem recorrer ao trabalho escravo. A difusão generalizada de uma instituição parece, a muitas pessoas, constituir uma prova convincente e irrefutável de sua necessidade. Talvez, como defende uma das variáveis dessa corrente, toda sociedade utiliza o trabalho escravo porque certos tipos de trabalho são tão difíceis ou tão degradantes, que nenhuma pessoa livre irá se dispor a fazê-lo e, portanto, a menos que haja escravos para realizar esses trabalhos, eles não serão realizados. Como dizia o ditado do sul dos EUA, alguém tinha de se sujar de lama, e as pessoas livres não iriam tolerar exercer essa função (HIGGS, 10/05/2010: N. do E.).

Para este Editor e comentarista sociocultural, à luz do que o próprio Higgs argumenta, a escravidão parece ter desempenhado um papel fundamental no fortalecimento econômico, político e cultural dos processos civilizatórios antigos e não apenas nos da Europa Pós Medieval. Esse dado é de relevância tal que, é de se supor que a mãode-obra escrava não só pode ter contribuído para que o Velho Continente enriquecesse e deixasse parte da Ásia milenar para trás, como também 
tenha alavancado os projetos coloniais europeus nos continentes americano e africano (HIGGS, 10/05/2010: N. do E.).

Dali em diante, apesar de alguns reveses e contratempos, os europeus ocidentais - e, mais tarde, seus primos coloniais na América do Norte - conseguiram progredir de modo contínuo e se distanciar economicamente do resto da humanidade. No século XVIII eles já estavam muito à frente dos chineses, para não mencionar em relação aos povos mais atrasados do mundo.

$\mathrm{E}$, até o presente, essa disparidade de riqueza continua extremamente significativa.

\section{DISCUSSÕES - O que houve?}

Como foi que o Ocidente teve êxito em gerar esse progresso econômico contínuo?

Historiadores e cientistas sociais já ofereceram várias hipóteses; porém, até o momento, nenhuma explicação única conseguiu ganhar aceitação geral. Ainda assim, certos elementos de uma determinada resposta conseguiram obter um amplo consentimento.

Deirde McCloskey afirma que houve uma mudança radical na mentalidade das pessoas. Houve uma modificação na atitude delas em relação ao empreendedorismo, ao sucesso empresarial e à riqueza em geral. O crescente individualismo da cultura ocidental, arraigado na Doutrina Cristã, também parece ter contribuído significativamente (LAL, 1998).

Adicionalmente, a fragmentação política dos povos europeus durante a Baixa Idade Média (momento situado entre os entre os Séculos XI e XIII: N. do E.) e o início do período moderno - um pluralismo político com centenas de jurisdições distintas - estimulou um processo 


\section{AKEDIA}

de experimentação institucional e tecnológica por meio do qual empreendedores puderam descobrir como tornar a mão-de-obra e o capital mais produtivo.

Fundamental a este dinamismo sustentado foi a importância crescentemente dada aos direitos de propriedade privada. Se as pessoas não confiam que haverá uma razoável chance de colherem os frutos de seus próprios esforços e investimentos, elas terão pouco ou nenhum incentivo para trabalhar duro e acumular capital físico, humano e intelectual. E, sem tal acumulação, é impossível haver um progresso econômico contínuo.

No entanto, estes direitos de propriedade, que se tornaram mais seguros e confiáveis, não simplesmente caíram do céu. Na maioria das vezes, os comerciantes adquiriram a proteção de tais direitos, por meio de pagamento de propinas aos barões medievais (nobres déspotas que extorquiam tributos) e aos aspirantes a reis que constituíam a fragmentada elite dominante da Europa ocidental (sobre itens que tratam do comportamento das elites na conjuntura sociocultural mais ampla, consultar em nossas Referências, também: HIGGS, 12/04/2017: N. do E.).

E, ainda em ambiente de N. do E., nos cabe, neste instante, evocar como paralelo e sem demérito algum ao país, tampouco a Mr. Higgs, uma questão bairrista brasileira, a qual se assemelha bastante ao que Higgs pontua em seu discurso, falando sobre a promiscuidade aparente entre certos setores da sociedade organizada, e o seu parque produtivo.

Recentemente, o Brasil tem vivido cenas viscerais no campo da política, da economia, da cultura. Depois da eleição que empossou o Presidente Jair Bolsonaro (01/01/2019), a sociedade se dividiu basicamente em dois grandes blocos: de um lado, os que apoiam o atual governo e que querem fazer a sociedade avançar e a economia 
prosperar; e, de outro lado, aqueles que são contra toda e qualquer iniciativa governamental neste sentido, preferindo, inclusive, cultivar a ideia de que receber do Estado as soluções para os problemas socioeconômicos é a melhor via a ser seguida. Contudo, vale lembrar, que 0:

O keynesiano vulgar ${ }^{4}$ não entende que o extremo ativismo político pode funcionar contra a prosperidade econômica, pois cria aquilo que chamo de "incerteza do regime", uma difusa e generalizada incerteza quanto à própria natureza da iminente ordem econômica, especialmente em relação a como o governo irá tratar os direitos de propriedade no futuro (HIGGS5, 1997). Esse tipo de incerteza desestimula especialmente os investidores, deixando-os temerosos de colocar dinheiro em projetos de longo prazo. Tais investimentos de longo prazo, que desapareceram dos EUA quase que por completo após 1929, só vieram a se recuperar plenamente após a Segunda Guerra Mundial (HIGGS, 06/11/2011: N. do E.).

Talvez seja por isso, isto é, pela aparente repetição histórica das "Incertezas do Regime", as quais geram ciclos de "Bolhas" e de "Depressão" econômica que se sucedem, mais ou menos ao sabor de maiores ou menores interferências políticas, que os analistas socioeconômicos, em 1993, criaram um índice para medir o grau de tensão nos mercados. Esse é o índice VIX (também chamado de "Índice do Medo", que é a sigla para a expressão "Volatility Index" / "Índice de Volatilidade": N. do E.).

A importância de se destacar a variável medida pelo VIX, no contexto entrecruzado entre o que postula Higgs quanto ao sujeito keynesiano e o nosso apontamento editorial complementar é tão elementar, que vimos que foi sob a prática do medo, que se deu no Brasil, no dia 09/09/2021, depois de um conturbado dia 07/09/2021, uma

\footnotetext{
${ }^{4}$ Mr. Higgs, dizendo "keynesiano vulgar", se refere ao indivíduo adepto de uma teoria econômica formulada pelo economista John Maynard Keynes (1883-1946), que defende que deve haver plena ação do Estado nas políticas econômicas de um país, para atingir o pleno emprego e o equilíbrio econômico (N. do E.).

${ }^{5}$ HIGGS, Robert. Regime Uncertainty: Why the Great Depression Lasted So Long and Why Prosperity Resumed after the War. In: The Independent Review 1, no. 4 (spring), 1997, p. 561-90.
} 


\section{AKEDIA}

violenta queda dos mercados e do ânimo social e político. Nesse dia, que pode ter sido um dos momentos de auge da polarização política contemporânea, o Presidente Bolsonaro agiu mais como um cidadão indignado e menos como um estadista - resumidamente, na vigência de uma "briga" entre os Poderes da República, a fala de Bolsonaro, no Dia da Independência, manifestou voto pela continuidade da briga (N. do E.).

Isso fez a Bolsa de Valores despencasse, baixando as cotações de ativos, criando instabilidade política e jurídica intensa, mas, bastou que, dois dias depois, no final da tarde de 09/09/2021, fosse divulgada uma nota de "recuo estratégico", via Redes Sociais, atribuída ao Presidente, mas sabidamente orientada e corredigida pelo Ex-Presidente e conselheiro de Bolsonaro, Michel Temer, que todo o medo se dissipasse, e que o IBOVESPA ${ }^{6}$ disparasse repentinamente, saindo de uma baixa depressiva, para uma alta retumbante (REUTERS, 2021). Isso não mostra tudo, mas põe frente a frente dois argumentos de Higgs: a) o do "keynesiano vulgar"; e, b) o das "incertezas do regime" (N. do E.).

No extremo [disso tudo], os comerciantes estabeleceram uma independência política nas cidades-estados, onde podiam exercer total controle sobre as instituições legais que davam suporte às suas atividades econômicas: "O fato de que a civilização europeia passou por uma fase em que foram criadas cidades-estados", de acordo com Sir John Hicks, "é essencial para se entender a divergência entre a História da Europa e a História da Ásia" (HICKS, 1969).

No final da Era Medieval, Veneza, Genova, Pisa e Florença eram as principais cidades de Europa. Mais tarde, Bruges, Antuérpia, Amsterdã e Londres assumiram a liderança. Cada cidade tinha sua própria milícia, a qual estava sempre pronta para defendê-la contra ameaças à sua autonomia político-econômica.

${ }^{6}$ O Índice BOVESPA é composto pela observação do comportamento de compras e vendas de 66 ações específicas, dentre um volume de perto de 500 ativos negociados na Bolsa de Valores de São Paulo (N. do E.). 
Para facilitar seus negócios, os comerciantes criaram seu próprio sistema jurídico. Com o intuito de fornecer uma rápida, barata e justa resolução para as contendas comerciais. Esta Lex Mercatoria ${ }^{7}$ criou instituições e precedentes que sobrevivem até o presente, e as quais encontram hoje expressão em um vasto sistema de resoluções alternativas (não-estatais) de contendas, como as arbitragens privadas.

A N. do E. lembra, aqui, que, na mesma linha de raciocínio que Higgs já assinala no parágrafo anterior, como prática de autodeterminação dos sistemas econômicos, trata-se de conduta também registrada nos sistemas socioculturais. Embora informal, a Lex Mercatoria e o Contrato Social ${ }^{8}$, constituem-se em expedientes normativos subjetivos, os quais, em alguns ordenamentos jurídicos, são dispositivos recepcionados como "Direito dos Costumes", enquanto que, noutros, são mais familiares os dispositivos oriundos do "Direito Objetivo":

Levanto essa questão porque, no que concerne ao chamado contrato social, frequentemente tive a chance de protestar dizendo que jamais havia visto tal contrato, muito menos havia sido consultado sobre meu consentimento quanto a ele. Para ser válido, um contrato requer oferta voluntária, aceitação e compensação. Como jamais recebi tal oferta de meus governantes, certamente jamais aceitei tal contrato; e, em vez de compensação, tudo que recebi dos meus governantes foram desconsideração, desrespeito e desdém - para não mencionar o fato de que os governantes, não obstante a ausência de qualquer acordo, sempre ameaçaram explicitamente me infligir grandes danos caso eu não obedeça aos seus éditos (HIGGS, 29/03/2021: N. do E.).

\footnotetext{
${ }^{7}$ Normas jurídicas que surgiam de forma espontânea ao longo do tempo, a partir de costumes. Estas eram aceitas e referendadas reciprocamente pelos atores do comércio internacional, sem nenhum vínculo com o ordenamento jurídico dos respectivos países envolvidos nas negociações (N. do E.).

${ }^{8}$ Para Jean Jacques Rousseau (1712-1778), o Contrato Social é um mecanismo, por meio do qual, o homem natural recupera a sua liberdade, por meio de uma adesão deste à sociedade civil, donde necessariamente se deverá abrir mão da primazia da individualidade em prol da soberania da coletividade (N. do E.).
} 


\section{AKEDIA}

Em alguns países, os comerciantes e industriais utilizavam sua influência política para introduzir suas instituições jurídicas consuetudinárias nas Leis estatais. Por causa da fragmentação política da Europa, governos que dificultavam excessivamente a vida dos empreendedores tendiam a perder comerciantes e seus negócios - e, por conseguinte, sua base tributária - para jurisdições concorrentes, de modo que a simples ameaça de tais perdas já fazia com que os governantes fossem mais contidos em sua fúria reguladora e tributária, dando aos empreendedores mais liberdade de manobra (ROSENBERG \& BIRDZELL JR., 1986).

A N. do E. aqui se faz pertinente, na medida em que entendemos existir uma não mencionada conexão entre esta Europa, política e economicamente dispersa, e os princípios fundadores do Liberalismo Clássico. Em certa medida, o instituto da Lex Mercatoria, per se, é resultante natural deste contexto socioeconômico desviante, emergindo mesmo como condição natural para que se tivesse alguma padronização dos processos e dos negócios:

O liberalismo clássico é um sistema de governo em que o estado detém apenas o monopólio da segurança e da justiça, e lida exclusivamente com estas questões, não se intrometendo em nada mais. Tendo essa definição em mente, é possível entender por que uma pessoa defenderia o liberalismo clássico. Mais de quarenta anos atrás, eu mesmo era um resoluto defensor deste sistema. As pessoas se tornam defensoras do liberalismo clássico por várias razões, sendo que as duas principais, as quais são interrelacionadas, são: 1) elas passam a entender que, se o objetivo é gerar prosperidade e paz, então o livre mercado funciona melhor do que sistemas econômicos controlados pelo governo; e 2) porque elas passam a acreditar que podem, com muita razão, reivindicar (seguindo um raciocínio um tanto lockeano) seus direitos à vida, à liberdade e à propriedade, sem sofrer coerção (HIGGS, 11/06/2013: N. do E.).

Neste sentido, as Cidades-Estados, em tese, originariamente se fundariam sobre o ideário Liberal, na medida em que "aceitam o governo, mas, somente com a condição de que o governo se mantenha 


\section{AKEDIA}

estritamente limitado a proteger as pessoas contra violências e fraudes que iriam injustamente privá-las de sua vida, liberdade e propriedade" (HIGGS, 11/06/2013: N. do E.).

[Logo, foi assim que] o grande enriquecimento começou para valer na Holanda, do século XVII. No século XVIII, o fenômeno já havia se espalhado para a Inglaterra, Escócia e as colônias americanas. Começou com o para-raios de Franklin e a máquina a vapor, de James Watt.

Isso foi expandido, nos anos 1820 (Século XIX), para uma nova invenção: as ferrovias com locomotivas à vapor. $E$, então, vieram as estradas macadamizadas ${ }^{9}$. Depois, surgiram as ceifadeiras, criadas por Cyrus McCormick, e as siderúrgicas, criadas por Andrew Carnegie. Ambos eram escoceses que viviam nos EUA.

Tudo se intensificaria ainda mais no restante do século XIX, e aceleraria fortemente no início do século XX.

Deu-se dignidade e liberdade à Classe Média pela primeira vez na história da humanidade, e esse foi o resultado: o motor à vapor, o tear têxtil automático, a linha de montagem, a orquestra sinfônica, a ferrovia, a empresa, o abolicionismo, a imprensa à vapor, o papel barato, a alfabetização universal, o aço barato, a placa de vidro barata, a universidade moderna, o jornal moderno, a água limpa, o concreto armado, os direitos das mulheres, a luz elétrica, o elevador, o automóvel, o petróleo, as férias, o plástico, meio milhão de novos livros em inglês por ano, o milho híbrido, a penicilina, o avião, o ar urbano limpo, direitos civis, o transplante cardíaco e o computador, feitos que redundaram no fato de que as pessoas comuns e, especialmente os mais pobres, tiveram sua vida melhorada.

\footnotetext{
9 Macadame (do inglês Macadam) é um tipo de pavimento para estradas desenvolvido pelo engenheiro escocês, John Loudon McAdam, acerca de 1820. O processo recebeu o nome de Macadam, dado em homenagem ao seu criador, e consiste em assentar três camadas de pedras postas numa fundação, com valas laterais dispostas para o enxugo da água da chuva (N. do E.).
} 
CONCLUSÕES - A retração da China e do mundo islâmico

Consequentemente, o Ocidente, que durante séculos havia ficado atrás da China e da civilização islâmica, se tornou incrivelmente inovador, a partir do século XVIII. Já, a China, que por séculos havia sido a grande potência do mundo, começou um fragoroso processo de retração.

Ao contrário dos comerciantes da Europa e, posteriormente, dos Estados Unidos, que conseguiam jogar um governo contra o outro em sua contínua busca por direitos de propriedade mais confiáveis, os empreendedores da China sofreram implacáveis ataques estatais de seu amplo e abrangente governo imperial (sobre modos e consequência de intervenção estatal na sociedade, consultar em nossas Referências, também: HIGGS, 05/08/2008 e 12/09/2019: N. do E.).

Já, em 1500, o governo decretou ser pena capital construir um navio com mais de dois mastros; e, em 1525, o governo ordenou a destruição de todas as embarcações construídas para navegação no oceano. Assim, a China, cujo comércio exterior havia sido vasto e abrangente durante séculos, impôs a si própria uma trajetória que a levaria à pobreza, à derrota e ao declínio.

Dentre várias outras ações adversas, o governo mandarim interrompeu o desenvolvimento de relógios e de máquinas industriais movidas a água por toda a China.

A título de N. do E., retomamos, de um texto de 2013, um trecho, em que Mr. Higgs já se apresentava como avesso à centralização social, política e econômica, particularmente quanto aos postulados emanados de Rússia, China e outros países propensos à mesma prática: 
Quando me tornei um libertário, comecei abraçando posturas consequencialistas ou utilitaristas, talvez por causa de minha formação como economista. Estava convencido de que uma sociedade livre seria mais rica, mais saudável e mais feliz certamente no longo prazo, se não imediatamente — do que uma sociedade controlada. Com base na teoria econômica e na história da economia, pude compreender os apavorantes fracassos das economias centralmente planejadas da URSS, da China, do Camboja e de outros países. Essa compreensão me impressionou e me pareceu ser um fundamento perfeitamente adequado para que qualquer um se tornasse adepto do libertarianismo (HIGGS, 13/02/2013: N. do E.).
\end{abstract}

No mundo islâmico, um governo imperial também esmagou o progresso econômico ao se mostrar incapaz de proteger direitos de propriedade e ao impor regulamentações e impostos arbitrários.

No século $X X$, o império soviético igualmente adotou a política de inventar e impor uma grande e péssima ideia - planejamento econômico centralizado - a qual suprimiu totalmente a liberdade econômica necessária para um progresso econômico contínuo e robusto.

Infelizmente, os comunistas chineses, os europeus do leste, e vários governos pós-coloniais do Terceiro Mundo seguiram o caminho aberto pela URSS, e foram à ruína econômica.

\title{
CONSIDERAÇÕES FINAIS - Hoje
}

Durante os últimos 20 séculos, as maiores economias do mundo foram China e Índia, exceto nos últimos dois séculos, o XIX e o XX, devido à ascensão do capitalismo no Ocidente. Com a chegada da economia de mercado ao Oriente, o século XXI poderá vivenciar a "volta à normalidade", com o retorno da populosa Ásia à liderança principalmente se as economias ocidentais continuarem demonstrando uma olímpica indiferença aos pilares básicos que permitiram a pujança do Ocidente. 


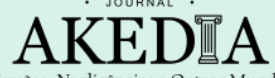

Em pleno século $X X I$, era de se esperar que, finalmente, as pessoas e os governos já houvessem entendido o elo inquebrantável entre liberdade econômica e crescimento econômico, e apreciassem a importância vital dos direitos de propriedade privada. Porém, e infelizmente, isso parece ainda não ser a realidade.

Contudo, o que podemos constatar, nesta derradeira N. do E., é que:

\begin{abstract}
[...] ao longo dos últimos 5.000-10.000 anos, para praticamente todos os seres humanos do mundo, o Estado sempre existiu e sempre esteve presente com suas depredações e abusos dos direitos humanos. Seu poder de dominar, subjugar e espoliar seus súditos é cuidadosamente sustentado pela sua destreza em explorar os medos humanos, dentre eles o medo dos indivíduos em relação ao próprio Estado e a outras ameaças à vida e à integridade, contra as quais o Estado jura que irá nos proteger. (Nessa postura, o Estado em nada se difere daquelas gangues de bairro que extorquem pessoas em troca de "proteção".) (HIGGS, 17/06/2015: N. do E.).
\end{abstract}

Desse modo, não é demasiado lembrar, que o verdadeiro poder advém e se mantém por meio do povo de uma Nação, ainda que o Estado e suas elites políticas predominantemente se ocupem de "três maneiras básicas de manter a população submissa e dócil aos seus mandos e desmandos: subornar, ameaçar e mentir" (HIGGS, 15/09/2016: N. do E.).

Em todos os cantos do globo, os governos continuam concedendo privilégios a grupos específicos, atacando empreendedores que genuinamente criam riqueza e impondo restrições que estrangulam a liberdade econômica.

Como a história perfeitamente mostra, os direitos de propriedade privada requerem uma contínua e inflexível defesa - caso contrário, as pré-condições para todo e qualquer progresso econômico serão solapadas e destruídas. 


\section{REFERÊNCIAS ORIGINAIS MANTIDAS}

HICKS, John. A Theory of Economic History. London: Oxford University Press, 1969 , p. 38.

LAL, Deepak. Unintended Consequences: The Impact of Factor Endowments, Culture, and Politics on Long-Run Economic Performance. Cambridge, Mass.: MIT Press, 1998, p. 75-97.

ROSENBERG, Nathan \& BIRDZELL JR., L. E. How the West Grew Rich: The Economic Transformation of the Industrial World. New York: Basic Books, 1986.

\section{REFERÊNCIAS MENCIONADAS PELA AKEDIA (NAS N. DO E.)}

HIGGS, Robert. Como Franklin Roosevelt piorou a Depressão. Instituto Mises Brasil, 05/08/2008. Disponível em: https://mises.org.br/article/130/comofranklin-roosevelt-piorou-a-depressao. Acesso em: 10/09/2021, às 16h19min.

HIGGS, Robert. Seis erros fundamentais da atual ortodoxia econômica. Instituto Mises Brasil, 06/06/2011. Disponível em: https://mises.org.br/article/1002/seis-erros-fundamentais-da-atual-ortodoxiaeconomica. Acesso em: 10/09/2021, às 16h19min.

HIGGS, Robert. Defender a liberdade: porque ela funciona ou porque é moralmente correto? Instituto Mises Brasil, 13/02/2013. Disponível em: https://mises.org.br/article/1524/defender-a-liberdade-porque-ela-funciona-ouporque-e-moralmente-correto. Acesso em: 10/09/2021, às 16h19min.

HIGGS, Robert. O sonho impossível do liberalismo clássico. Instituto Mises Brasil, 11/06/2013. Disponível em: https://mises.org.br/article/1621/o-sonhoimpossivel-do-liberalismo-classico. Acesso em: 10/09/2021, às 16h19min.

HIGGS, Robert. Dez conclusões falaciosas da ideologia dominante. Instituto Mises Brasil, 17/10/2013. Disponível em: https://mises.org.br/article/1371/dezconclusoes-falaciosas-da-ideologia-dominante. Acesso em: 10/09/2021, às 16h19min.

HIGGS, Robert. Por que as pessoas se submetem aos desmandos do estado e de seus políticos. Instituto Mises Brasil, 17/06/2015. Disponível em: https://mises.org.br/article/1905/por-que-as-pessoas-se-submetem-aosdesmandos-do-estado-e-de-seus-politicos. Acesso em: 10/09/2021, às 16h19min. 


\section{AKED』A}

HIGGS, Robert. Estes são os verdadeiros três poderes do governo. Instituto Mises Brasil, 15/09/2016. Disponível em: https://mises.org.br/article/2514/estessao-os-verdadeiros-tres-poderes-do-governo. Acesso em: 10/09/2021, às 16h19min.

HIGGS, Robert. Sejamos francos: a política é assalto organizado. Instituto Mises Brasil, 12/04/2017. Disponível em: https://mises.org.br/article/2561/sejamos-francos-a-politica-e-assaltoorganizado. Acesso em: 10/09/2021, às 16h19min.

HIGGS, Robert. Todas as políticas governamentais são bem-sucedidas no longo prazo. Instituto Mises Brasil, 24/07/2017. Disponível em: https://mises.org.br/article/2729/todas-as-politicas-governamentais-sao-bemsucedidas-no-longo-prazo. Acesso em: 10/09/2021, às 16h19min.

HIGGS, Robert. Por que políticas de estímulos e intervenções governamentais geram recessões. Instituto Mises Brasil, 12/09/2019. Disponível em: https://mises.org.br/article/2598/por-que-politicas-de-estimulos-e-intervencoesgovernamentais-geram-recessoes-. Acesso em: 10/09/2021, às 16h19min.

HIGGS, Robert. O contrato social e o consentimento do governado. Instituto Mises Brasil, 29/03/2021. Disponível em: https://mises.org.br/article/1043/ocontrato-social-e-o-consentimento-do-governado. Acesso em: 10/09/2021, às 16h19min.

REUTERS. Ao encontro do que a maioria dos brasileiros espera": políticos comentam declaração à nação de Bolsonaro. Bolsonaro divulgou nota no final da tarde com conteúdo apaziguador, declarando respeito pelas instituições, 09/09/2021. Disponível em: https://www.infomoney.com.br/politica/ao-encontrodo-que-a-maioria-dos-brasileiros-espera-politicos-comentam-declaracao-anacao-de-bolsonaro/. Acesso em: 10/09/2021, às 13h46min. 